BIORHEOLOGY, 22; I-III, 1985

$0006-355 \times / 85 \$ 3.00+.00$ Printed in the USA.

Copyright (c) 1986 Pergamon Press Ltd. A11 rights reserved.

EDITORIAL:

SOFTWARE SURVEY SECTION

The introduction of the new Software Survey Section to BIORHEOLOGY is to encourage the open exchange of information on software programs unique to our professional field. With the rapid penetration of computers into academic and industrial institutions has come a parallel increase in the nuniber of scientists and researchers designing their own software. The existence of much of this software remains unknown to even those of us who could most benefit from its use. We believe that it is of vital importance to our readers that such information be made available. We believe also that a professional journal is the best place to share such information. Your contribution would be most welcome.

The questionnaire on the following pages is designed to assist you in reporting on software that you may have developed or be in the process of developing. By completing this form, your information will reach thousands of your colleagues who may benefit from your work and may possibly offer suggestions for further enhancements to your software. Please complete the enclosed form and return it to:

Dr. Richard Skalak

Depariment of Civil Engineering

Columbia University

Seeley W. Mudd Building

New York, New York 10027 USA

We do not intend to review or comment on the contents of the questionnaire. It will be published as is in order to expedite the information cycle process. I would welcome any comments you may have. 
NAME OF JOURNAL BIORHEOLOGY

\section{PERGAMON PRESS}

SOFTWARE DESCRIPTION FORM

Title of software package:

It Is: [ ]Application program [ ]Utility [ ]0ther

Specific area

(e.g. Thermodynamics, Inventory Control)

Software developed for [name of computer(s)]

in [1 anguage $(\mathrm{s})]$

to run under [operating system]

and is available in the following media:

[ ] Floppy disk/diskette. Specify: Size Density

[ ]Single-sided [ ]Dual-sided

[ ] Magnetic tape. Specify: Size Density

Character set

Distributed by:

Minimum hardware configuration required:

Required memory:

User training required: $[$ ]Yes $[$ NNo

Documentation: $[$ ]None $[$ ]Minimal $[$ ]Self-documenting

[ ]Extensive external documentation

Source code available: [ ]Yes [ ]No

Level of development: [ ]Design complete [ ]Coding complete

[ ]Fully operational [ ]Collaboration would be welcomed

Is software being used currently? [ ]Yes [ ]No

If yes, how long? If yes, how many sites?

Contributor is available for user inquiries: $[$ ]Yes $[$ NNo

Return completed form to:

Dr. Richard Skalak Department of Engineering

Columbia University

Seeley W. Mudd Building

New York, New York 10027

(continued)

[This Software Description Form may be photocopied without permission] 
Description of what software does [200 words]:

Potential users:

Fields of interest:

Name of contributor:

Institution:

Address:

Telephone number:

\section{\#\#\#\#\#\#\#}

Reference No. [Assigned by Journal Editor]

[The information below is not for publication.]

Would you like to have your program:

Reviewed? $[$ YYes [] No $[$ Not at this time

Marketed and distributed? $[$ JYes $[$ No $[$ Not at this time

[This Software Description Form may be photocopied without permission] 